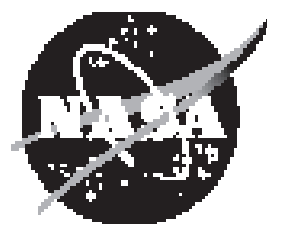

\title{
Modeling Vortex Generators in the Wind-US Code
}

Julianne C. Dudek

Glenn Research Center, Cleveland, Ohio 


\section{NASA STI Program . . . in Profile}

Since its founding, NASA has been dedicated to the advancement of aeronautics and space science. The NASA Scientific and Technical Information (STI) program plays a key part in helping NASA maintain this important role.

The NASA STI Program operates under the auspices of the Agency Chief Information Officer. It collects, organizes, provides for archiving, and disseminates NASA's STI. The NASA STI program provides access to the NASA Aeronautics and Space Database and its public interface, the NASA Technical Reports Server, thus providing one of the largest collections of aeronautical and space science STI in the world. Results are published in both non-NASA channels and by NASA in the NASA STI Report Series, which includes the following report types:

- TECHNICAL PUBLICATION. Reports of completed research or a major significant phase of research that present the results of NASA programs and include extensive data or theoretical analysis. Includes compilations of significant scientific and technical data and information deemed to be of continuing reference value. NASA counterpart of peer-reviewed formal professional papers but has less stringent limitations on manuscript length and extent of graphic presentations.

- TECHNICAL MEMORANDUM. Scientific and technical findings that are preliminary or of specialized interest, e.g., quick release reports, working papers, and bibliographies that contain minimal annotation. Does not contain extensive analysis.

- CONTRACTOR REPORT. Scientific and technical findings by NASA-sponsored contractors and grantees.
- CONFERENCE PUBLICATION. Collected papers from scientific and technical conferences, symposia, seminars, or other meetings sponsored or cosponsored by NASA.

- SPECIAL PUBLICATION. Scientific, technical, or historical information from NASA programs, projects, and missions, often concerned with subjects having substantial public interest.

- TECHNICAL TRANSLATION. Englishlanguage translations of foreign scientific and technical material pertinent to NASA's mission.

Specialized services also include creating custom thesauri, building customized databases, organizing and publishing research results.

For more information about the NASA STI program, see the following:

- Access the NASA STI program home page at http://www.sti.nasa.gov

- E-mail your question via the Internet to help@ sti.nasa.gov

- Fax your question to the NASA STI Help Desk at $443-757-5803$

- Telephone the NASA STI Help Desk at 443-757-5802

- Write to: NASA Center for AeroSpace Information (CASI) 7115 Standard Drive Hanover, MD 21076-1320 


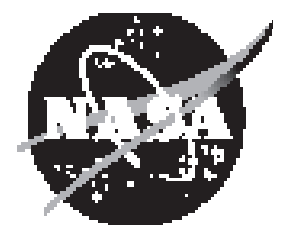

\section{Modeling Vortex Generators in the Wind-US Code}

Julianne C. Dudek

Glenn Research Center, Cleveland, Ohio

Prepared for the

48th Aerospace Sciences Meeting

sponsored by the American Institute of Aeronautics and Astronautics

Orlando, Florida, January 4-7, 2010

National Aeronautics and

Space Administration

Glenn Research Center

Cleveland, Ohio 44135 


\section{Acknowledgments}

The author would like to sincerely thank Rodrick Chima, Mary Jo Long-Davis and Charles Towne of the NASA Glenn Research Center, and Chris Nelson of Innovative Technology Applications Company, LLC.

This work was sponsored by the Fundamental Aeronautics Program at the NASA Glenn Research Center.

Level of Review: This material has been technically reviewed by technical management.

Available from

NASA Center for Aerospace Information 7115 Standard Drive

Hanover, MD 21076-1320
National Technical Information Service 5301 Shawnee Road Alexandria, VA 22312

Available electronically at http://gltrs.grc.nasa.gov 


\title{
Modeling Vortex Generators in the Wind-US Code
}

\author{
Julianne C. Dudek \\ National Aeronautics and Space Administration \\ Glenn Research Center \\ Cleveland, Ohio 44135
}

\begin{abstract}
A source term model which simulates the effects of vortex generators was implemented into the Wind-US Navier Stokes code. The source term added to the Navier-Stokes equations simulates the lift force which would result from a vane-type vortex generator in the flowfield. The implementation is userfriendly, requiring the user to specify only three quantities for each desired vortex generator: the range of grid points over which the force is to be applied and the planform area and angle of incidence of the physical vane. The model behavior was evaluated for subsonic flow in a rectangular duct with a single vane vortex generator, supersonic flow in a rectangular duct with a counter-rotating vortex generator pair, and subsonic flow in an S-duct with 22 co-rotating vortex generators. The validation results indicate that the source term vortex generator model provides a useful tool for screening vortex generator configurations and gives comparable results to solutions computed using a gridded vane.
\end{abstract}

\section{Introduction}

In modern aircraft engine inlets, vortex generators (VGs) are frequently used to improve performance by minimizing the effects of adverse pressure gradients, boundary layer separations and shock-boundary layer interactions. Vortex generators come in many shapes and sizes, but in this paper, vane-type VGs are the focus. These VGs are small vane-shaped devices mounted at an angle to the local flow, and introduce streamwise vortices which act to mix the high-momentum flow in the freestream with the low-momentum flow near the wall. This can be an effective means of preventing or reducing flow separation, thereby improving the performance of an inlet or wing.

Computational Fluid Dynamics (CFD) is used to simulate inlet flow and predict inlet performance, and together with experiments and statistical methods, is a useful tool in designing new inlets. Inlets occasionally include multiple VGs, and in studies where multiple VG arrays must be evaluated, it is very time-consuming and impractical to generate computational grids for each VG. Therefore, it is highly desirable to be able to model the effects of the VGs without including their geometry in the computational mesh.

With this in mind, NASA Glenn has implemented two vortex generator models into the Wind-US Navier-Stokes code (Refs. 1 to 3). Previous work describes the Wendt empirical VG model and its implementation (Refs. 4 and 5). This model was primarily developed for subsonic flows with adverse pressure gradients, and simulates the VG by adding vorticity as a step change at a give axial station. More recently, a lift-force model, developed by Bender, Anderson and Yagle (Ref. 6) and referred to in this paper as the "BAY" model was implemented into Wind-US. This is a more robust model applicable to a wider range of flows, including supersonic flows and sub-boundary layer VGs. It acts over the length of the VG, rather than at a single axial station, allowing it to accurately simulate longer VGs. Both models are user-friendly; the user only needs to specify the generator location, dimensions and angle of incidence.

In this paper, the implementation of the BAY vortex generator model into the Wind-US code is described. The differences between the Wendt and BAY models are highlighted. Validation results for a single vane in subsonic flow, a pair of counter-rotating vanes in supersonic flow and also an array of vanes in a subsonic S-duct diffuser are given. 


\section{Nomenclature}

$\begin{array}{ll}\hat{b} & \text { unit vector in the direction of the span of the vortex generator } \\ c_{V G} & \text { model constant } \\ c & \text { vortex generator chord length } \\ D C 60 & \text { pressure distortion index } \\ E & \text { total energy } \\ F_{E} & \text { inviscid and viscous fluxes in energy equation } \\ \vec{F}_{M} & \text { inviscid and viscous fluxes in momentum equations } \\ h & \text { vortex generator height } \\ \vec{L}_{i} & \text { vortex generator source term on cell } i \\ \hat{l} & \text { a unit vector in the direction of the lifting force acting on the flow } \\ \hat{n} & \text { unit vector normal to the vortex generator } \\ p & \text { static pressure } \\ p_{0 \infty} & \text { freestream total pressure } \\ S_{j} & \text { area of cell face j } \\ S_{V G} & \text { vortex generator planform area } \\ \vec{u} & \text { velocity vector } \\ \hat{u} & \text { unit velocity vector } \\ V_{i} & \text { volume of cell } i \\ \hat{t} & \text { unit vector tangent to the vortex generator planform } \\ x, y, z & \text { Cartesian coordinates } \\ y & \text { nondimensionalized } y \text {-coordinate } \\ \alpha & \text { vortex generator angle of incidence } \\ \Delta t & \text { time step } \\ \delta & \text { boundary layer thickness } \\ \rho & \text { density } \\ \omega^{+} & \text {peak vorticity } \\ \xi, \eta, \zeta & \text { computational coordinates }\end{array}$

\section{The Wind-US CFD Code}

The Wind-US CFD code (Refs. 1 to 3) may be used to solve the Euler or Navier-Stokes equations of fluid mechanics, along with supporting equation sets governing turbulent and chemically reacting flows. The code has structured, unstructured and hybrid grid capability, although all cases described in this paper use structured grids and the current implementation of the vortex generator models is valid only for structured grids. The Wind-US code is the production solver of the NPARC Alliance, which is a partnership between NASA Glenn Research Center (GRC), the USAF Arnold Engineering Development Center (AEDC), and the Boeing Company. The mission of the Alliance is to develop, validate and support an integrated, general purpose, computational flow simulator for the U.S. aerospace community; the work described in this paper contributes to these efforts. The code itself uses a finite-volume formulation and allows the user to select from several schemes to compute both the right-hand-side inviscid terms, as well as the left-hand-side viscous terms.

Wind-US has two vortex generator models: the Wendt model (Refs. 4 and 5) and the recently added BAY model (Ref. 6). Both models may be used to model a single vane-type vortex generator, or an array of vortex generators. The Wendt model was developed primarily for subsonic flows with vanes having heights on the order of the boundary layer thickness and having moderate height-to-chord ratios. It must 
be applied at a coupled zonal interface boundary, where the effects of the vortex generators are simulated by a step change in the secondary velocities (Ref. 5). The strength of each vortex is based on the user input vortex generator chord length, height and angle of incidence with the primary flow, as well as the local velocity and boundary layer thickness. These vortex generator parameters are shown in Figure 1.

The BAY model was developed to handle a wider range of vortex generator geometric parameters including "micro-vanes" which have small heights ( 25 to 40 percent of boundary layer thickness) and vanes with large chord lengths, and may be used in subsonic and supersonic flows. The details of the BAY model are given below.

\section{The BAY Vortex Generator Model}

The vortex generator model implemented in the Wind-US Navier-Stokes code adds a source term to the momentum and energy equations which simulates the lift force introduced by a vane VG in the flowfield. This source term was developed by Bender, Anderson and Yagle (Ref. 6) and acts to align the local flow velocity with the vane VG. The lifting force source term, $\vec{L}_{i}$, acting at grid point $i$, is added to the governing discretized finite volume momentum and energy equations:

$$
\begin{gathered}
V_{i} \frac{\Delta(\rho \vec{u})_{i}}{\Delta t}=\sum_{j} \vec{F}_{M_{j}} S_{j}+\vec{L}_{i} \\
V_{i} \frac{\Delta(\rho E)_{i}}{\Delta t}=\sum_{j} F_{E_{j}} S_{j}+\vec{u} \bullet \vec{L}_{i}
\end{gathered}
$$

where,

$$
\vec{L}_{i}=c_{V G} S_{V G} \frac{V_{i}}{\sum V_{i}} \alpha \rho|\vec{u}|^{2} \hat{l}
$$

and $\hat{l}$ is a unit vector in the direction of the lifting force acting on the flow. This force is equal and opposite to the force which would act on the vane. $\vec{u}$ is the local velocity, $\rho$ is the local density, $\alpha$ is the angle of incidence of the vane with the primary flow, $V_{i}$ is the volume of the grid cell, and $\Sigma V_{i}$ is the sum of the volumes of all of the cells over which the model is being applied, $S_{V G}$ is the VG planform area, and $c_{V G}$ is an empirical constant. The model constant, $c_{V G}$ controls the strength of the side force and the intensity with which the local velocity aligns with the vane.

The vane VG is described by three unit vectors, as shown in Figure 2, where $\hat{b}$ is along the span of the vane, $\hat{t}$ is tangent to the vane and $\hat{n}$ is normal to the vane and perpendicular to $\hat{b}$ and $\hat{t}$. Using the small angle approximation, the unit vector $\hat{l}$ is assumed to be normal to the velocity vector and the unit vector $\hat{b}$ along the VG span,

$$
\hat{l}=\frac{\vec{u}}{|\vec{u}|} \times \hat{b} \equiv \hat{u} \times \hat{b}
$$

where $\hat{u}$ is a unit vector in the flow direction and

$$
\alpha \approx \sin \alpha=\cos \left(\frac{\pi}{2}-\alpha\right)=\hat{u} \bullet \hat{n}
$$


The lift force source term is also multiplied by a factor of

\section{$\hat{u} \bullet \hat{t}$}

to approximate the loss of side force at higher angles of attack. The resulting equation for the lift force source term is

$$
\vec{L}_{i}=c_{V G} S_{V G}\left(\frac{V_{i}}{\sum V_{i}}\right) \rho|\vec{u}|^{2}(\hat{u} \bullet \hat{n})(\hat{u} \times \hat{b})(\hat{u} \bullet \hat{t})
$$

In determining the value of the constant $c_{V G}$, Bender et al. (Ref. 6) calibrated it by examining the integrated cross-flow kinetic energy, $\sqrt{\kappa}$. They found that for large values of $c_{V G}, \sqrt{\kappa}$ approaches an asymptotic value because the VG model source term, $\vec{L}_{i}$, starts to dominate the other terms in the governing equations. This causes the flow to align itself with the vortex generator, resulting in a local angle of attack which approaches zero, i.e. $\hat{u} \bullet \hat{n} \approx 0$, so that the lift force goes to zero when the local flow becomes aligned with the vane. Bender et al. suggest that this asymptotic behavior is reached for $c_{V G}>5$. Jirasek (Ref. 7) found that the flow in an s-duct is independent of the value of $c_{V G}$ for values greater than 7. The default value for $c_{V G}$ in Wind-US is 10 , but may be changed by the user.

This implementation of the BAY vortex generator model into the Wind-US code was designed to be user- friendly. The unit vectors $\hat{b}, \hat{t}$, and $\hat{n}$, are computed within the code based on the user inputs, reducing the time and effort needed to set up inputs. Within the standard Wind-US keyword input file, the user specifies the following information for each vortex generator to be modeled: the range of grid points over which the model is to be applied, the planform area of the physical vane, and the angle of incidence the vane makes with the primary grid direction.

\section{Test Cases}

\section{A Single Vane in Subsonic Flow}

The first validation case run with the BAY VG model was a single vortex generator on a flat plate in subsonic flow. For comparison, simulations were also run with the vane gridded in the computational mesh. Results are compared with the experimental data of Yao, et al. (Ref. 8).

\section{Experimental Configuration}

In the experiment of interest, a single vane VG with an angle of incidence of $16^{\circ}$ was mounted on a long flat plate at a location where the local boundary thickness, $\delta$, is approximately $35 \mathrm{~mm}$. (See Fig. 3) The flow was turbulent with a freestream velocity of $U=35 \mathrm{~m} / \mathrm{s}$. Stereo digital particle image velocimetry measurements were taken using two cameras taking simultaneous pictures of the cross-flow plane from opposite angles and directions. All three velocity components were obtained through stereoscopic reconstruction. The VG was a rectangular flat plate with a height of $7 \mathrm{~mm}(h / \delta=0.2)$ and a chord length of $49 \mathrm{~mm}(c / h=7)$. It is considered a "low-profile" VG (Ref. 8) (or "sub-boundary layer" VG (Ref. 9)) since the height is much less than the boundary layer thickness (Ref. 8).

\section{Computational Strategy}

The boundary layer at the vane was set up by creating a long duct section $(266 \mathrm{~cm}$ long) upstream of the specified vane location; this was the length required for the boundary layer thickness to grow to the desired $35 \mathrm{~mm}$ at the vane leading edge. The model was applied at the station where $\delta=35 \mathrm{~mm}$. The farfield boundaries were defined to be sufficiently far from the vane to avoid influence: the grid height is $30 \mathrm{~cm}$, and the grid width is $40 \mathrm{~cm}$. In the experiment, the dimensions of the duct were $51-$ by $71-\mathrm{cm}$. A 
smaller computational grid was used to reduce the number of grid points, thereby reducing the computational time. Inviscid wall boundary conditions were set at the side and top boundaries. A viscous wall boundary was set at the lower wall, and the grid was clustered such that $y^{+}=0.8$ at the first point from the wall. Freestream atmospheric conditions were specified at the inflow with the total temperature and pressure held constant. The mass flow rate at the outflow was specified as $10.75 \mathrm{lbm} / \mathrm{sec}(4.88 \mathrm{~kg} / \mathrm{s})$. This produced the desired Mach number of 0.1 in the duct.

For the gridded vane solution the vane had zero thickness. Two grids were created: one which was nearly identical to that used for the BAY model calculations and used inviscid boundary conditions on the vane, and another which used viscous wall boundary conditions on the vane. The latter grid was packed at the vane wall $\left(y^{+} \approx 1.6\right)$ with viscous wall boundary conditions specified. The grid using the viscous wall boundary condition had dimensions $279 \times 101 \times 64$ for a total of $1,803,456$ grid points. The grid for the inviscid vane boundary condition case had dimensions $279 \times 91 \times 64$ and $1,625,796$ total points, a reduction of only 10 percent, since fairly fine resolution is required to capture the vortex, as described below. In both grids, the vane grid size was $22 \times 2 \times 36$.

Local time stepping was used to integrate to a steady state flowfield. The default second-order upwind-biased Roe scheme with modifications for stretched grids was used for the explicit right-handside terms and the default full block implicit scheme was used to compute the viscous terms. The Mentor shear stress transport (SST) turbulence model was used. The solution was considered converged when the L2 residuals had leveled off and the peak vorticity was no longer changing.

For the simulations performed using the BAY model, the model was applied to the rectangularshaped region where the vane was located within the grid, as shown in Figure 4(c). These points envelop the region of the physical vane inclined at $16^{\circ}$, and have grid dimensions $22 \times 9 \times 36$. Generally in the vicinity of the vortex generator, a grid spacing of 30 percent of the vane chord in each coordinate direction is adequate, based on Reference 5. However, these recommendations were based on vanes which had more than double the height-to-chord ratio of the sub-boundary-layer vane, and heights which were on the order of the boundary layer thickness. To make sure the vortex details were captured for a vane with a smaller height, a maximum spacing of 30 percent of the vane height was used instead. At the vane trailing edge tip, the resulting grid spacing in each coordinate direction was: $\Delta x / h=0.32, \Delta y / h=$ $0.24, \Delta z / h=0.17$. To confirm that the current grid resolution was adequate simulations were run using a grid where the number of points was halved in each direction, and another grid where the number of points was doubled in each direction. The corresponding grid dimensions of the rectangular-cylindershaped region where the BAY model was specified were $12 \times 5 \times 18$ and $44 \times 19 \times 72$, respectively. Based on these results the current grid was determined to have sufficient resolution for these calculations. Doubling the number of points gave neglible benefit, while halving the grid did not provide sufficient resolution to capture the details of the vortex upstream quite as well as the chosen grid. The grid used for the model simulations is shown in Figure 4; the cross-plane region where contours of velocity and vorticity are shown in later figures is also highlighted, for perspective.

\section{Simulation Results}

Velocity contours downstream of the vane are shown for the experiment, the two gridded vane solutions, and the BAY model solution in Figure 5. Six axial stations are shown, measured from the vane trailing edge and nondimensionalized by the vane height. The gridded vane solution with viscous walls does the best job of simulating the vortex shape and detail for $\Delta x / h \leq 10$. Progressing downstream, the differences between the viscous vane solution and the inviscid vane and BAY model solutions diminish. For all stations shown, the velocity contours for the inviscid vane solution are nearly identical to those of the BAY model solution. Note that due to limitations of the plotting software, it was not possible to match the color distribution within the velocity scale for the CFD results exactly to that shown from Reference 8 for the experimental data, however a best effort was made.

Vorticity contours are shown in Figure 6. (Note that three different scales are used.) All simulation results underpredict the maximum vorticity magnitude, indicating a less concentrated vortex than shown 
experimentally. All of the simulation results are very similar in magnitude and shape, indicating that there is little benefit to using viscous wall vanes to generate a tip vortex. Note that the BAY model, unlike a viscous vane calculation, does not model the losses generated by the VGs, and may thus give optimistic answers. For predicting these vorticity contours, the BAY model gives essentially the same result as both gridded vane solutions.

The axial decay of the peak vorticity is plotted in Figure 7. The gridded vane solutions and the BAY model solution underpredict the initial peak vorticity shown in the experiment. The experimental value of peak vorticity at the first experimental measurement station at $\Delta x / h=1.6$ is approximately $72001 / \mathrm{s}$. The corresponding values for the CFD simulations are significantly less; the resulting values are 2400 1/s for the gridded vane, $2700 \mathrm{1} / \mathrm{s}$ for the gridded vane with viscous walls, and $2600 \mathrm{1} / \mathrm{s}$ for the BAY model simulation. Of the simulations, the gridded vane solutions have slightly higher vorticity in the upstream region where $\Delta x / h$ is between 3 and 20, but further downstream, it decays to the levels of the BAY model. This rapid decay of the peak vorticity is also seen in References 8 and 10 and is currently unexplained.

Also, since vorticity is defined as the difference between velocity gradients, it is also very sensitive to grid resolution. To see if a grid finely packed at the location of the vane tip would significantly improve the result, a simulation was run with a grid very finely packed at the location of the vane tip see (Fig. 7(b)). The cross-plane resolution was 75 percent finer in the horizontal direction and 94 percent finer in the vertical direction. The peak vorticity resulting from the simulation using this grid is included in Figure 7(a), as the "fine tip grid" case. The initial peak vorticity is much higher than previous simulations as well as the experiment, however, it also decays very quickly, as in the previous simulations. This indicates the complexity of accurately predicting the peak vorticity and its axial decay. A more accurate comparison of peak vorticity would be found by interpolating the CFD results onto the same "grid" used to compute the vorticity in the experiments. Unfortunately, the experimental grid information was not available for this comparison. But in summary, one sees that, in general, in Reynolds-averaged NavierStokes CFD results, the vortex decays more rapidly than experimental results. Overall, for these calculations, the BAY model is easier to use than gridding the vanes, and produces a very similar result.

\section{A Counter-Rotating Vortex Generator Pair in Supersonic Flow}

This validation case was run to demonstrate that the BAY model may also be used to simulate vanes in supersonic channel flow. The case for counter-rotating vanes in Mach 2.0 flow was simulated and results were compared with a solution computed with the vanes gridded within the computational mesh. At the time of this writing, experimental data for a single or multiple vanes in shock-free supersonic flow could not be obtained. Data does exist for vanes in the vicinity of normal and oblique shocks, however the computation of shock waves introduces its own challenges and may be studied in conjunction with vane VGs at a later date.

\section{Configuration and Computational Strategy}

The flow conditions for this case were Mach 2.0 with a freestream velocity of $506 \mathrm{~m} / \mathrm{s}$, total pressure of $101.4 \mathrm{KPa}$, and total temperature of $287.2 \mathrm{~K}$. The VG array consisted of two low-profile flat plate vane VGs at angles of incidence of $+16^{\circ}$ and $-16^{\circ}$, with a chord length $c$ of $3.6 \mathrm{~cm}$ and a height $h$ of $0.36 \mathrm{~cm}$ $(c / h=10)$. The leading edge of the vanes was located $100 \mathrm{~cm}$ from the inflow boundary where the boundary layer thickness $\delta$ was $1.05 \mathrm{~cm}(h / \delta=0.34)$. A schematic of this configuration is shown in Figure 8 .

The boundary layer at the vane was set up in a manner similar to that of the vane in subsonic flow. A long duct section (100 cm long) was created upstream of the vanes to allow the boundary layer thickness

to grow to $1.05 \mathrm{~cm}$ at the vane leading edge. Since the geometry was symmetric about the centerline plane between the vanes, only half of the duct was gridded, with a symmetry boundary condition applied on the plane midway between the vanes as well as on the opposite sidewall. The lower wall was specified as a viscous wall and at the first grid point from the wall, $y^{+}$was equal to 0.5 ; the upper boundary was set to an 
inviscid wall. Inviscid wall boundary conditions were used on the vane for the gridded vane case. The inflow was set to freestream conditions, and at the outflow boundary the pressure was extrapolated. The duct was $195 \mathrm{~cm}$ long, $15.25 \mathrm{~cm}$ high and $2.5 \mathrm{~cm}$ wide. The grid had four zones. Zone 1 had dimensions of $41 \times 21 \times 64$; zone 2 had dimensions of $100 \times 45 \times 64$; zone 3 had dimensions of $21 \times 45 \times 64$; and zone 4 had dimensions of $21 \times 21 \times 64$ for a total of 431,808 points. The vane was located in zone 2 , and so a denser grid was used in zones 2 and 3 to capture the vortex features. The vane was specified within zone 2 and had dimensions $23 \times 6 \times 36$.

The Wind-US code was run using local time stepping with the Mentor SST turbulence model in a manner similar to the vane in subsonic flow. The solution was considered converged when the L2 residuals had leveled off and area averaged total pressure recovery was changing by less than 0.0001 .

\section{Simulation Results}

The Mach number at five axial locations in the duct is shown in Figure 9 for the solutions computed using the gridded vane and the BAY model. The axial stations given are nondimensionalized by the vane height. The VG pair produces a counter-rotating "upward" pair of vorticies, meaning that the two vorticies are rotating in the upward and outward direction in the centerplane where they meet. At the first axial station of $x / h=5$, the two vortex shapes can be seen fairly distinctly. For the gridded vane case the shape of the vortices is more clearly defined. As the vortex pair moves downstream the two vorticies move closer together and upward, away from the wall. The differences in the BAY model solution from the gridded vane solution diminish with downstream progression, and at $x / h=100$, the shape of the Mach contours is very similar.

The counter-rotating upward pair of vortices produced by the vane pair is similar to the vortex pair produced by a micro-ramp VG. Figure 10 shows the experimental data of Hirt et al (Ref. 11). for a microramp VG and the corresponding Mach contours at an axial station of $\Delta x / h=15$. The similarity of the shape for the Mach contours indicates that it is likely that, with proper calibration, the BAY model is a likely candidate for simulating micro-ramp vortex generators by treating them as a pair of vanes at opposite angles of incidence.

\section{Flow in a Circular S-Duct}

In this study, flow in a circular S-duct was examined for throat Mach numbers ranging from approximately 0.35 to 0.80 . The purpose of the study was to evaluate Wind-US with the BAY VG model for an aggressively diffusing flow containing vane-type VGs. The results were compared with experimental data and with Wind-US simulations with the VGs represented as gridded flat plate vanes, and with previous results of simulations using the Wendt VG model (Ref. 5).

\section{Experimental Configuration}

The geometry which was tested experimentally is test case 3 from the AGARD study of Reference 12 and was labeled the M2129 duct in the experimental investigations of Anderson and Gibb (Ref. 13). This duct has a circular cross-section and an S-shaped centerline, as shown in Figure 11. The duct was approximately $2 \mathrm{ft}(0.61 \mathrm{~m})$ in length, and the throat, which is located at the end of the upstream straight section, was 5.06 in. $(12.9 \mathrm{~cm})$ in diameter. The engine face, or aerodynamic interface plane (AIP) was located at 19.27 in. $(48.9 \mathrm{~cm})$, its diameter is $6.0 \mathrm{in} .(15.2 \mathrm{~cm})$, and the duct offset was $5.4 \mathrm{in} .(13.7 \mathrm{~cm})$. The duct had a length to inlet diameter, $L / D_{i}$ of 4.74 , and the engine face to inlet area ratio, $A_{e f} / A_{i}$, was 1.40 , with an offset of $\Delta z / D$ of 1.07 . A centerbody with a cross-sectional area of about 7 percent of the AIP, not shown, protruded upstream from the duct outlet and extended through the AIP. This centerbody was not modeled in the CFD investigation. A 72-probe pitot rake positioned at the engine face, was used to measure the engine face total pressure recovery and distortion. It consisted of twelve 6-probe rakes spaced $30^{\circ}$ apart. 
The VG configuration tested is referred to as VG170 in Ref. 13 and contains 11 flat plate vanes per half duct, located two inlet radii downstream of the inlet throat. Each VG had a height-to-chord ratio of 0.25 , where the chord was approximately 0.7 in. $(1.8 \mathrm{~cm})$, and an angle of incidence of $16^{\circ}$. The incidence was chosen in order to turn the flow near the wall away from the bottom of the duct, to counteract the formation of the duct vortex.

\section{Computational Strategy}

The computational grids used for the simulations with the VGs gridded as flat plates and with the VG effects simulated with the VG model were very similar in terms of the number of points and clustering. The grid used for the BAY model simulations is shown in Figure 12. Since the duct is symmetric about the $\mathrm{x}$-z-plane only half of the duct was gridded. The grids include a straight, $10.14 \mathrm{in} .(25.76 \mathrm{~cm})$ long constant-area section at the upstream end of the duct, in order to allow a boundary layer to develop, and another 5.07 in. $(12.88 \mathrm{~cm})$ constant-area section at the downstream end, so that the computational boundary is aft of the AIP. For the gridded vane simulations the vanes were specified using inviscid wall boundary conditions, and the grid had 718,000 points, with the sections upstream and downstream of the vane each having dimensions of $13 \times 277 \times 50$ and the VG section having dimensions of $11 \times 277 \times 50$. The value of $y^{+}$at the duct wall was 0.8 . The BAY model was specified over the 11 individual grid regions containing each VG, each region having dimensions of $10 \times 2 \times 25$. The grid spacing at the VG trailing edge nondimensionalized by the VG chord length was 0.10 in the axial direction, 0.05 in the radial direction, and 0.04 in the circumferential direction. For the cases computed using the Wendt VG model, the grid was split at the vane trailing edge station, and the Wendt model was applied at this zonal interface. For simulations using the VG models the grid had a total of 679,000 points, 6 percent fewer points than used for the gridded vane. Again, a fine grid resolution near the vortices was desired to accurately capture the features of the vortices.

Five cases, with throat Mach numbers ranging from 0.35 to 0.80 , were run with the VGs specified. The different throat Mach numbers were a result of the set value of the outflow static pressure, and the downstream pressure ratios $p / p_{0_{\infty}}$ were those used by Mohler (Ref. 14): 0.938, 0.877, 0.861, 0.841, and 0.826 . The corresponding throat Mach numbers were $0.40,0.62,0.68,0.75$ and 0.82 .

Local time stepping was used to integrate to a steady state flowfield. The default second-order upwind-biased Roe scheme with modifications for stretched grids was used for the explicit right-handside terms and the default full block implicit scheme was used to compute the viscous terms. The SpalartAllmaras (SA) turbulence model was used. The cases converged after approximately 15,000 iterations, based on the criteria that the total pressure recovery at the AIP as well as the Mach number at the throat had converged to within at least 3 significant figures.

\section{Results}

In the discussion of results which follows, the Wind-US results computed with the BAY model are compared with experimental data (Ref. 13) and previously computed results using gridded vanes and the Wendt model (Ref. 5).

The total pressure recovery versus throat Mach number is plotted in Figure 13(a) for the baseline cases and Figure 13(b) for the cases with VG's in the duct. Note that neither the Wendt model nor the BAY model formulations explicitly model the total pressure losses caused by the drag forces present on

the vane. This shortcoming is more apparent in the Wendt model total pressure recovery values, which are significantly higher than the experimental values; more so than the other computational results. For the lower throat Mach numbers, the vortex generators have little to no effect on recovery. At the higher throat Mach numbers ranging from 0.65 to 0.8 , however, there is a slight improvement. The VGs redistribute the low pressure flow more uniformly around the duct, resulting in a slight improvement in the area averaged total pressure. This behavior can be better understood by examining the total pressure contours and streamline plots of Figure 14(a) to (d) for a throat Mach number of 0.82 . 
In the streamline plots shown in Figure 14(a) to (d), the streamlines were released at the VG trailing edge station, and the total pressure contours are plotted at an axial location of $\Delta x / c=1$, or one chord length downstream of the VG trailing edge, and at the AIP station $(\Delta x / c=20)$. In the baseline case shown in Figure 14(a), flow separates on the lower surface of the duct, but reattaches just upstream of the AIP, however at the AIP a significant low pressure region remains at the base of the duct. This large region of low pressure results in an undesirable high level of distortion. The streamlines show that the low pressure flow at the VG station remains near the lower surface of the duct along the axial length of the duct and through the low pressure region at the AIP.

The total pressure contours from the experiment and the CFD solutions at the AIP show that the vanes have redistributed the flow and removed the low pressure region at the bottom of the duct. The streamlines illustrate the movement of the low energy flow up around the circumference of the duct, resulting in an overall more uniform total pressure distribution. The BAY model AIP total pressure contour distribution gives a slightly better match to the gridded vane solution than the Wendt model result, but the two model solutions are very similar.

The DC60 distortion is plotted in Figure 15. The DC60 distortion parameter is defined at the AIP to be the difference between the mean total pressure and the mean total pressure in the "worst" $60^{\circ}$ sector, normalized by the mean dynamic pressure (Ref. 15). The average improvement in DC60 as a result of the addition of the VGs was 82 percent for the experiment, 86 percent for the simulations using the gridded vane, 86 percent for the simulations using the Wendt model and 86 percent for the simulations using the BAY model. So in terms of the DC60 distortion parameter, there appears to be no added benefit to gridding the vane versus using either VG model.

In summary, the VG's have a minimal impact on the total pressure recovery in this duct, with only a slight benefit at the higher throat Mach numbers, so use of the BAY VG model versus gridded vanes makes little difference. For the distortion, the VG's greatly improve the distortion by redistributing the low pressure region around the circumference of the duct. The results using the BAY model versus the gridded vanes were essentially equivalent, however using the BAY model was much easier than gridding up vanes.

\section{Conclusion}

A lift-force source term vortex generator model for vane-type VGs was implemented into the WindUS CFD code for structured grid applications. The magnitude of the lift-force is based on the local flow conditions and the size and angle of orientation of the vane. The model is user-friendly and allows the user to specify the vanes by inputting the range of grid points enveloping each vane, the planform area of the vane and its angle of incidence. Validation results have been shown for a single vane in a subsonic channel, a counter rotating pair of vanes in supersonic flow, and an S-duct with a co-rotating array. For these test cases, the CFD results using the model were comparable to CFD results using a gridded vane. Since the model is easier to use than a gridded vane, the VG model is recommended as an efficient alternative to gridding vanes.

\section{References}

1. Bush, R.H., Power, G.D. and Towne, C E., "WIND: The Production Flow Solver of the NPARC Alliance," AIAA-98-0935, Jan. 1998.

2. Towne, C.E., "Wind-US User's Guide, Version 2.0," NASA/TM-2009-215804, Oct. 2009.

3. Nelson, C.C., Lankford, R. H., Nichols, R. H., "Recent Improvements to the Wind (-US) Code at AEDC," AIAA-2004-527, Jan. 2004.

4. Wendt, B.J., "Initial Circulation and Peak Vorticity Behavior of Vortices Shed from Airfoil Vortex Generators," NASA/CR_-2001-211144, Aug. 2001. 
5. Dudek, J.C., "Empirical Model for Vane-Type Vortex Generators in a Navier-Stokes Code," AIAA Journal, Vol. 44, No. 8, 2006, pp. 1779-1789.

6. Bender, E.E., Anderson, B.H., Yagle, P.J., "Vortex Generator Modeling for Navier-Stokes Codes," ASME Paper FEDSM99-6929, Jul. 1999.

7. Jirasek, A., "Vortex-Generator Model and Its Application to Flow Control," Journal of Aircraft, Vol. 42, No. 6, Nov.-Dec. 2005.

8. Yao, C-S, Lin, J.C., and Allan, B.G., "Flow-Field Measurement of Device-Induced Embedded Streamwise Vortex on a Flat Plate," AIAA-2002-3162, Jun. 2002.

9. Wik, E., and Shaw, S.T., "Numerical Simulation of Micro Vortex Generators," AIAA-2004-2697, Jan. 2004.

10. Dudek, J.C., "An Empirical Model for Vane-type Vortex Generators in a Navier-Stokes Code," AIAA-2005-1003, Jan. 2005.

11. Hirt, S.M., and Anderson, B.H., Experimental Investigation of the Application of Microramp Flow Control to an Oblique Shock Interaction," AIAA-2009-0919, Jan. 2009.

12. AGARD Fluid Dynamics Panel, Working Group 13, "Air Intakes for High Speed Vehicles," AGARD-AR-270, Sep. 1991.

13. Anderson, B.H., and Gibb, J., "Vane Effector Installation Studies on Steady State and Dynamic Inlet Distortion," AIAA-1996-3279.

14. Mohler, R.S., "WIND-US Flow Calculations for the M2129 S-Duct Using Structured and Unstructured Grids," NASA/CR—2003-212736, Jan. 2003.

15. Wendt, B.J., and Dudek, J.C., "Development of Vortex Generator Use for a Transitioning High-Speed Inlet," Journal of Aircraft, Vol. 35, No. 4, Jul. 1998. 


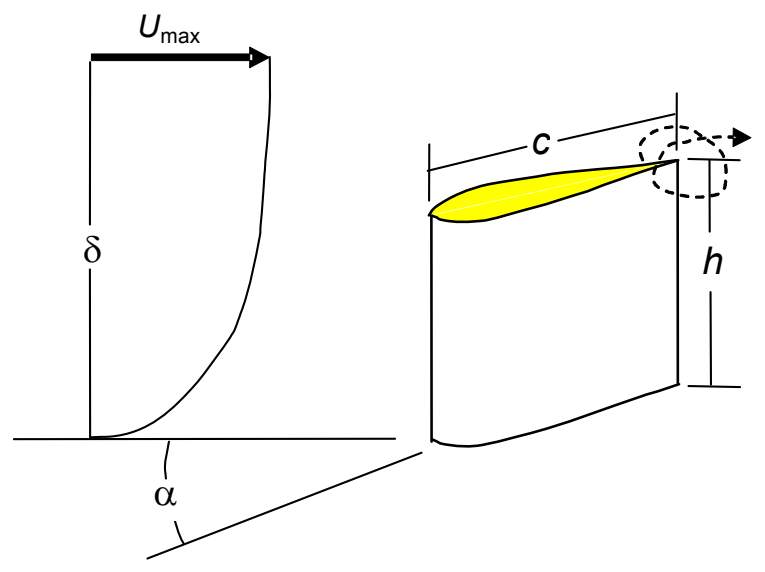

Figure 1.-Vortex generator model parameters.

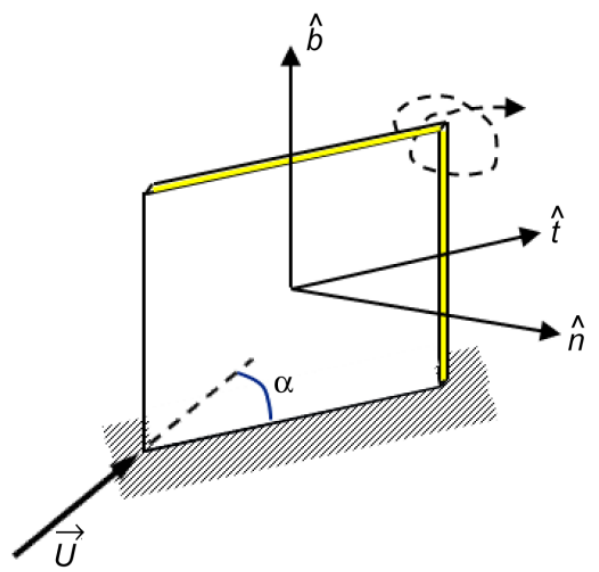

Figure 2.-Orientation of unit vectors on vane.

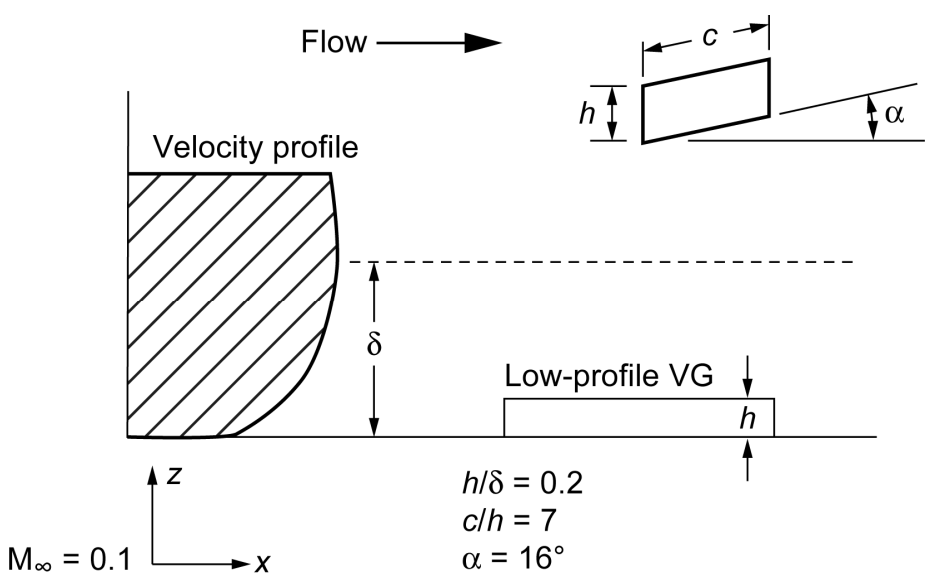

Figure 3.-Schematic of the single vane in subsonic flow test case of Yao et al. (Ref. 8). 


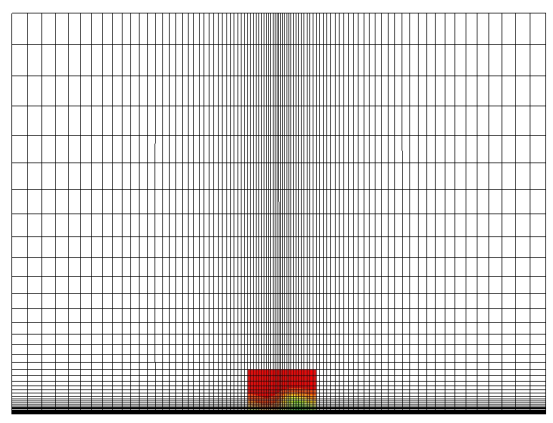

(a)

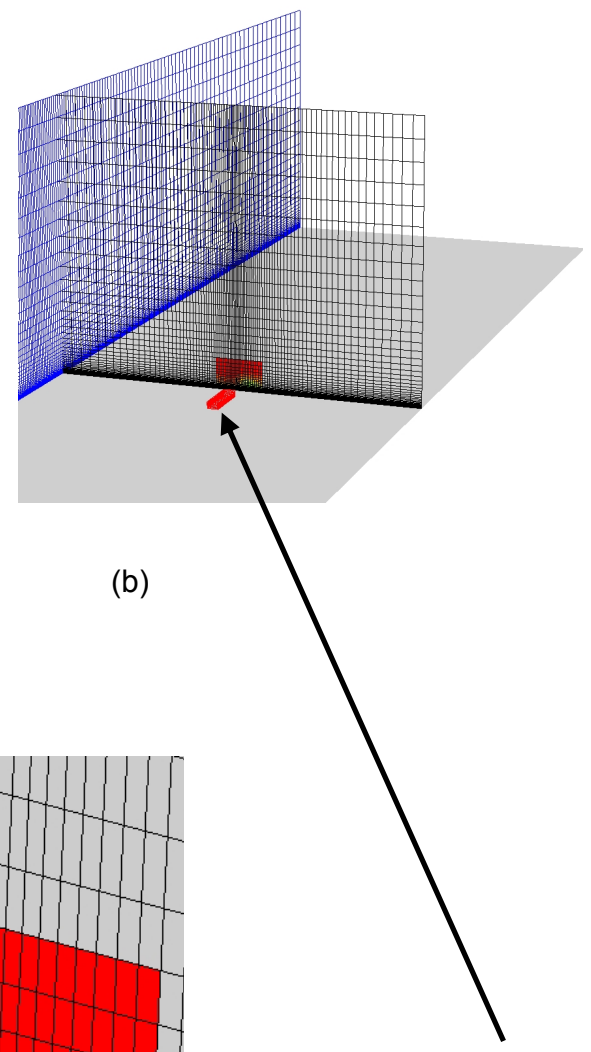

Region where source term model is specified

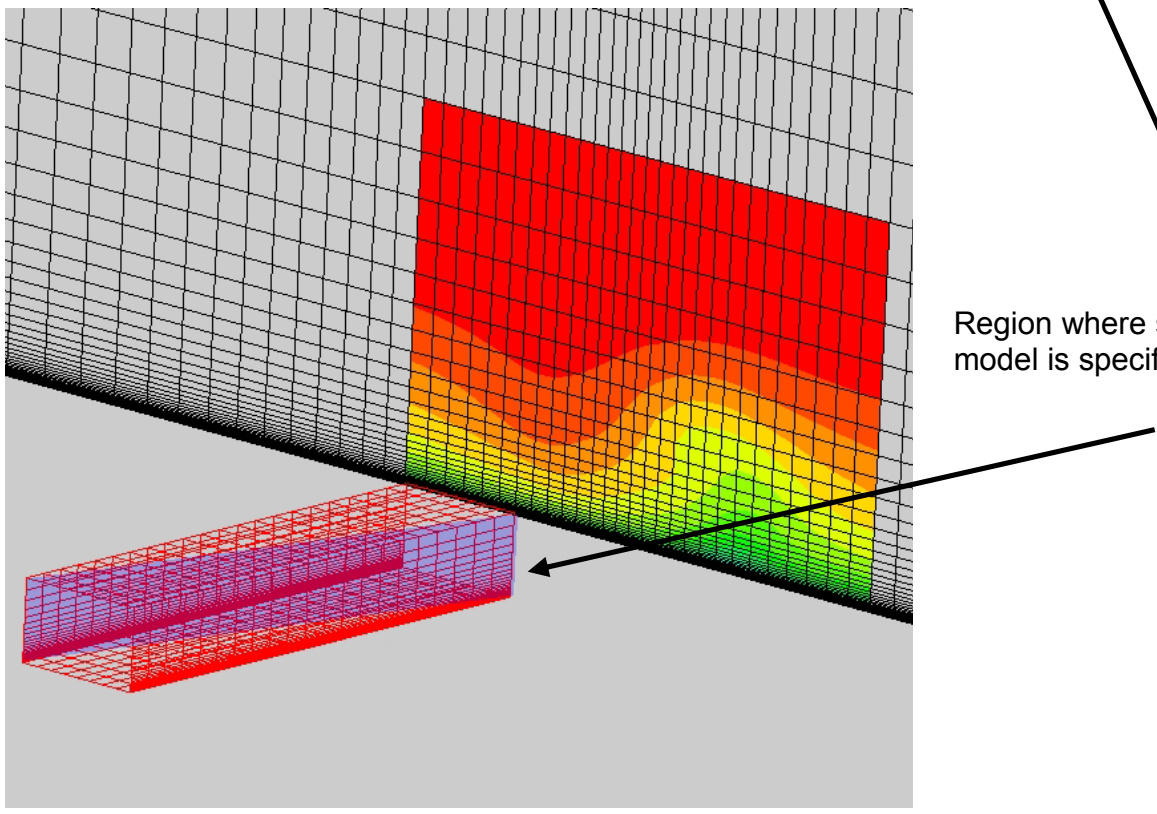

(c)

Figure 4.-Grid used for the BAY model simulations of the Yao single vane experiment (Ref. 8). Region where contours are shown in later figures given for perspective. (a) Cross-plane grid. (b) Isometric view showing axial grid spacing and (c) Region showing grid points (in red) where the BAY model is applied. 
$\Delta x / h$

3

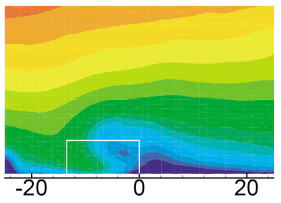

5

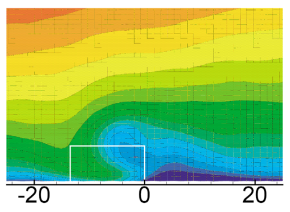

10

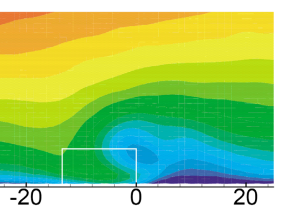

17

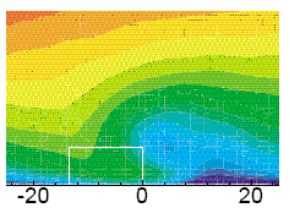

50

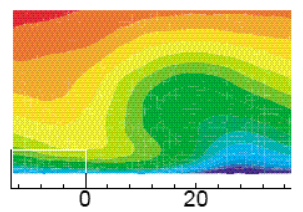

109

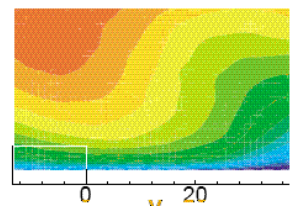

Experiment
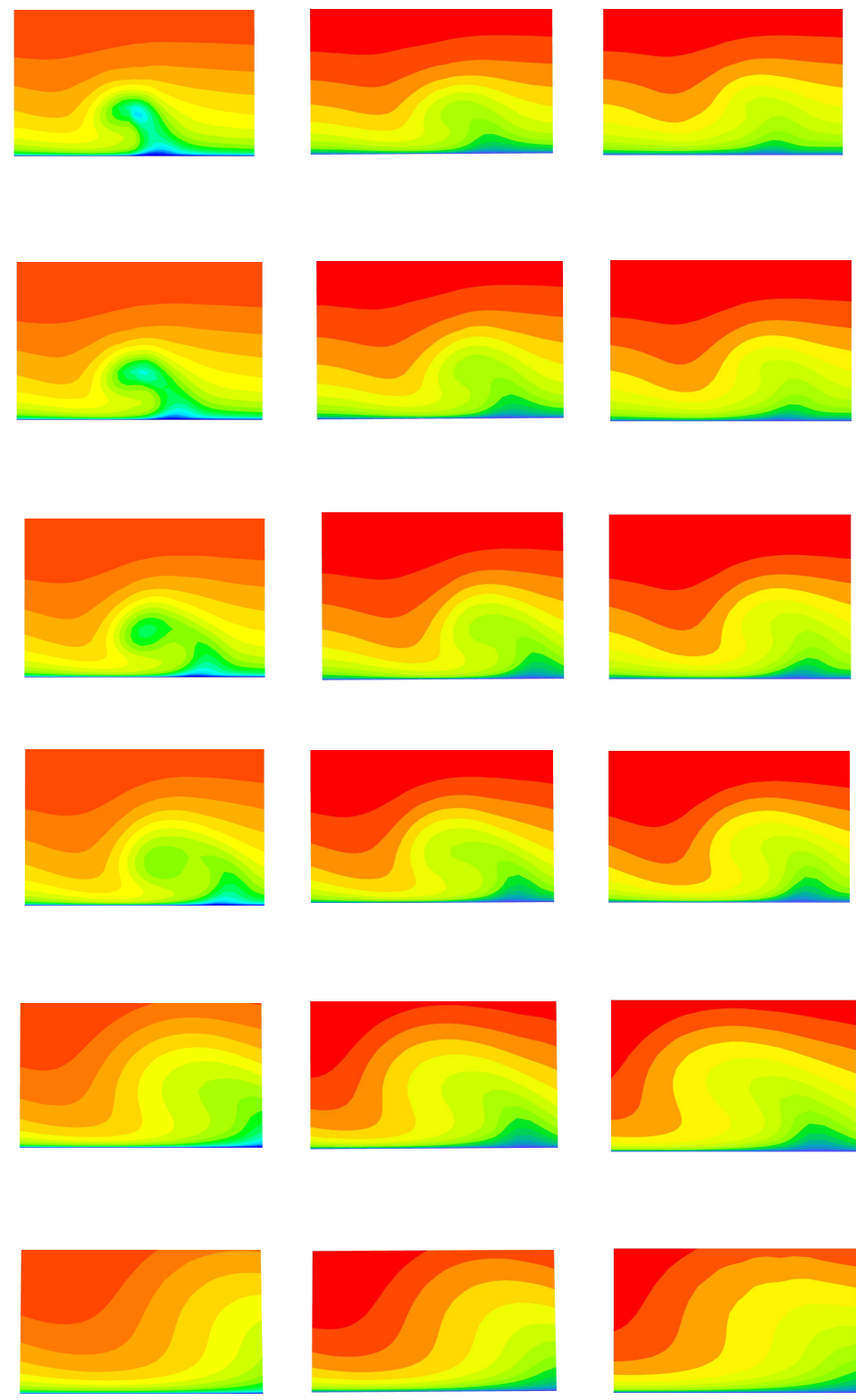

Gridded Vane/ Viscous Walls

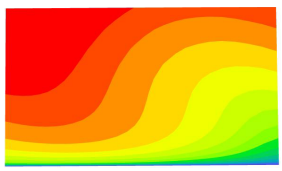

Gridded Vane

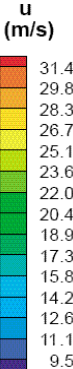

31.4
-29.8
28.3
26.7
25.1
23.6
22.0
20.4
18.9
17.3
15.8
14.2
12.6
11.1
9.5

\section{5}


$\Delta x / h$

3
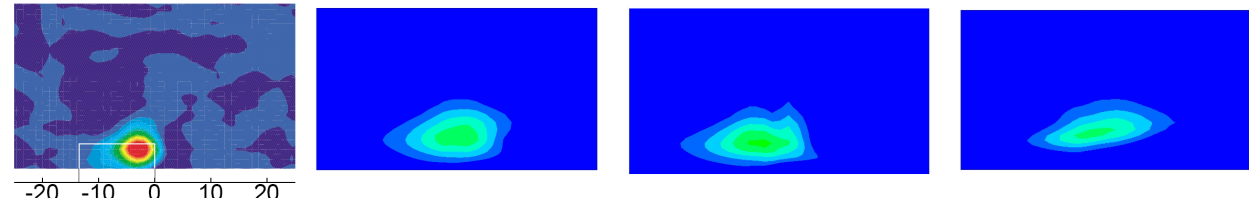

$\omega_{\mathrm{x}}$

5.0

5.5
-4.5
-4.0
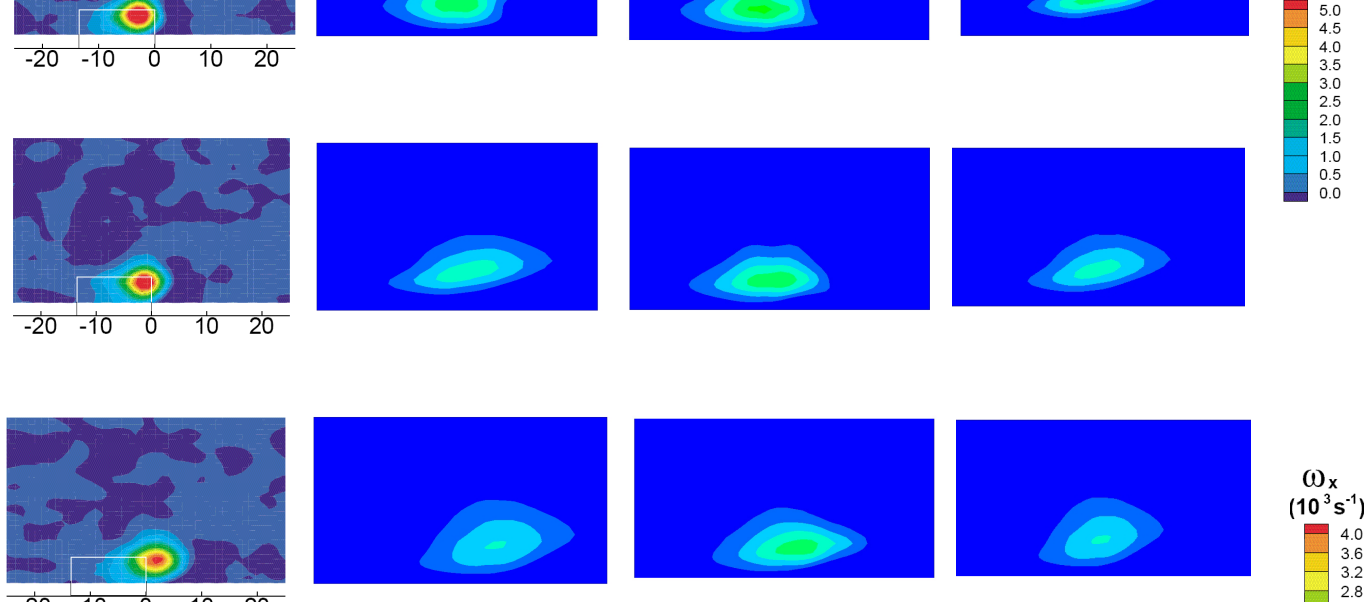

$\omega_{x}$

10
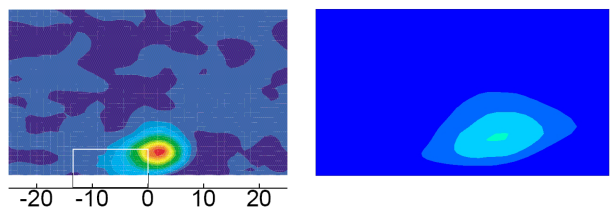

$\left(10^{3} s^{-1}\right)$

17
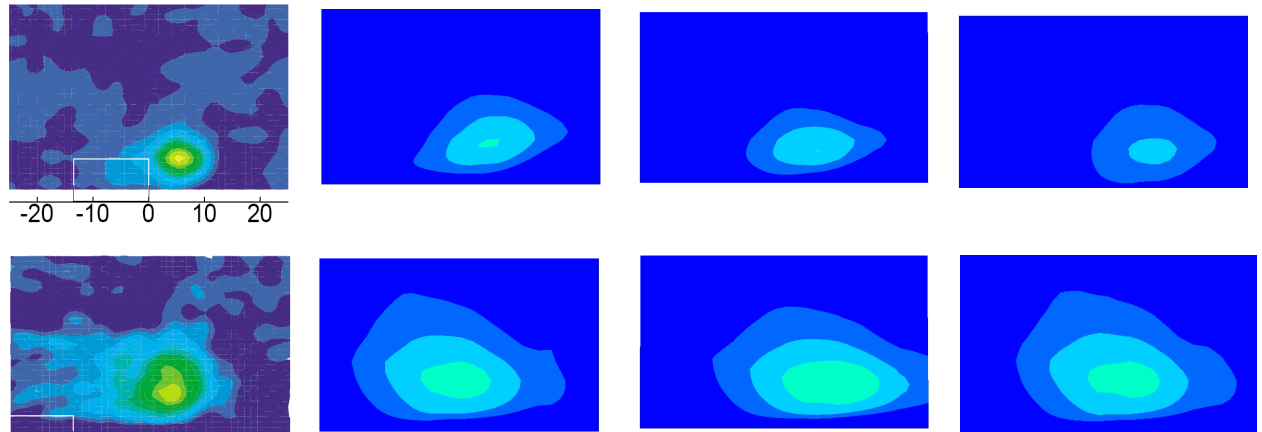

$\omega_{x}$
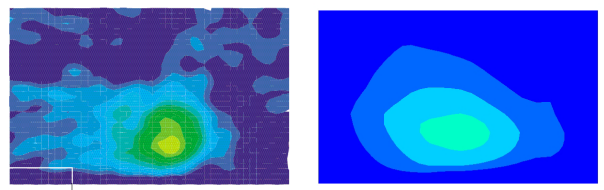

$\begin{array}{lllll}-10 & 0 & 10 & 20 & 30\end{array}$

109
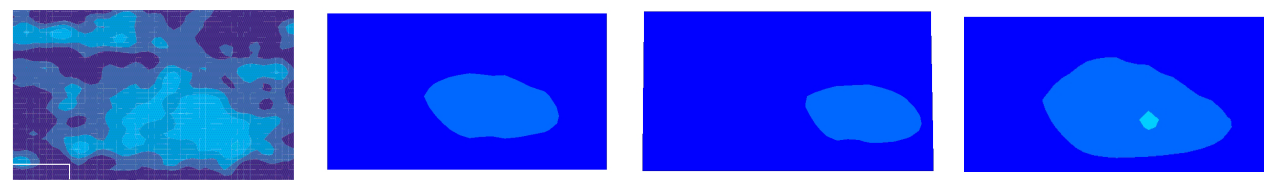

$\left(10^{3} \mathrm{~s}^{-1}\right)$

1.0
0.9

1.0
-0.9
-0.8

$\begin{array}{r}0.8 \\ -0.7 \\ -0.6 \\ \hline\end{array}$

0.6
0.5
0.4
0.3

$\begin{array}{llllll}-10 & 0 & 10 & 20 & 30 & 40\end{array}$

Experiment

Gridded Vane/ Viscous Walls

Gridded Vane

BAY Model

Figure 6.-Vorticity contours at six stations downstream of VG for the experiment and three simulations. 


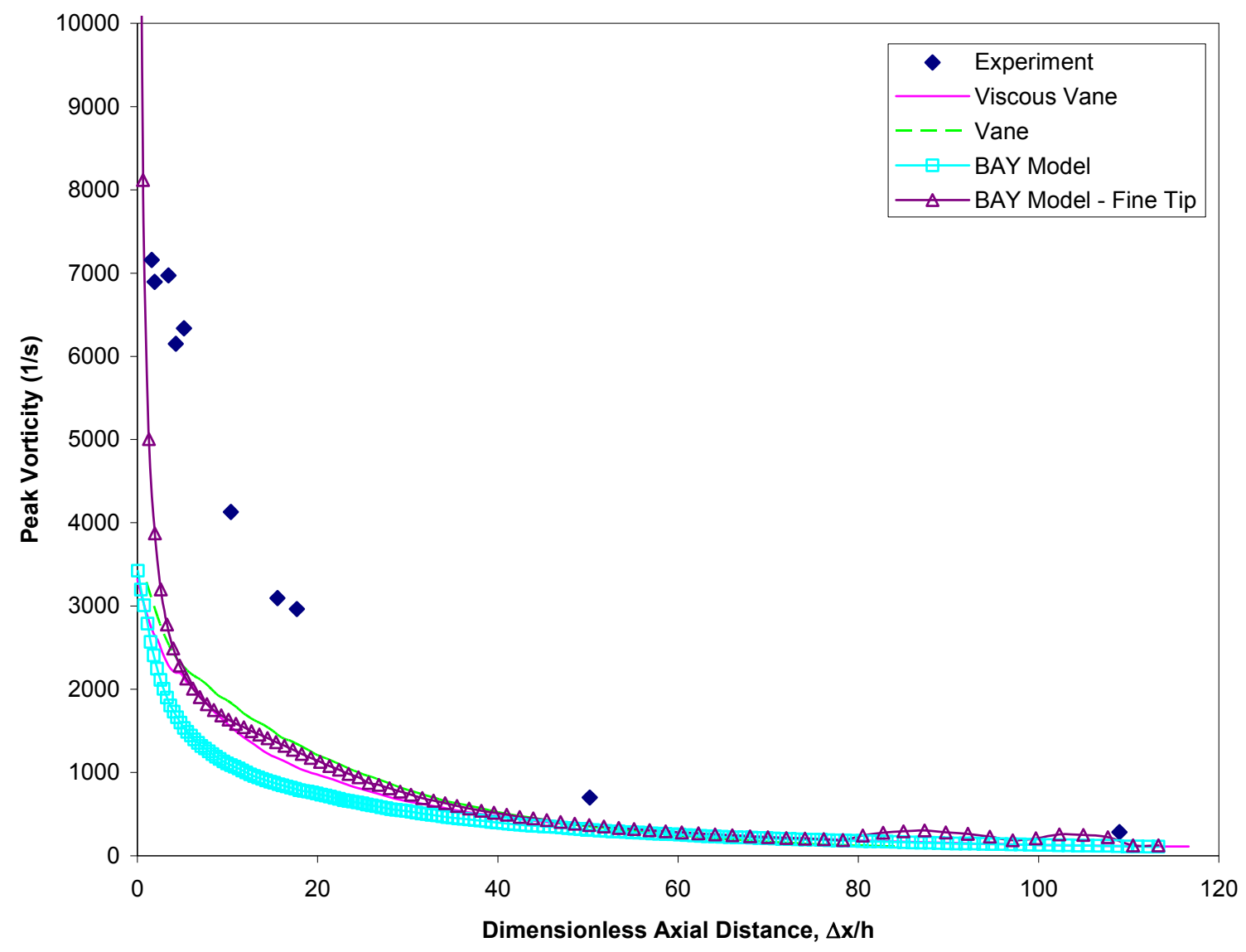

(a) Peak vorticity for the experiment and four CFD simulations.

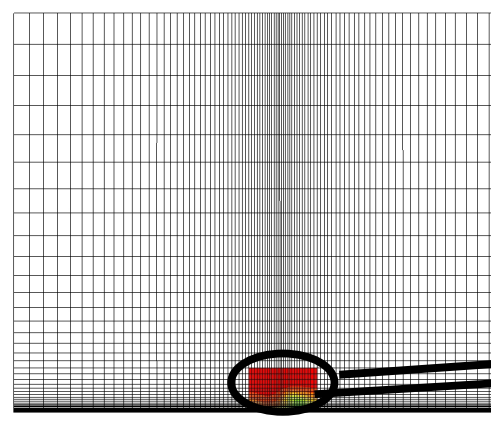

Cross Plane Grid at $x / h=3$ BAY Model Original Grid BAY Model Fine-Tip Grid

(b) Grid resolution for the BAY model original grid and BAY model grid packed finely at the vane tip.

Figure 7.-Peak vorticity versus axial direction (a) and cross-plane grids to illustrate grid resolution used for BAY model simulations (b). 


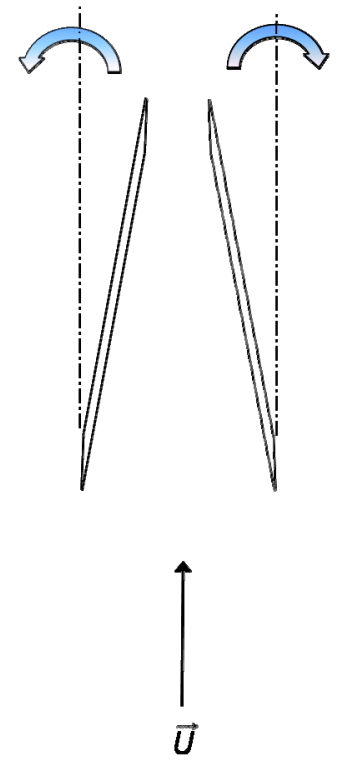

Figure 8.-Schematic of counterrotating vortex generators producing an upward vortex pair. 
$\Delta x / h$

5
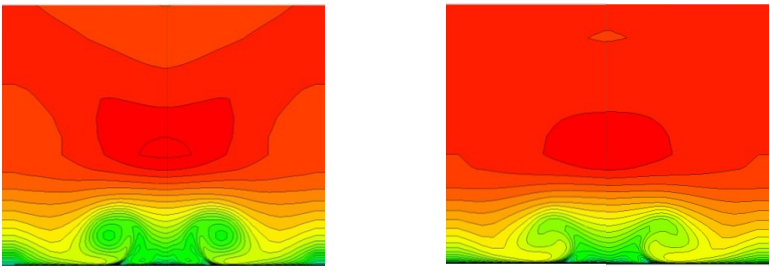

Mach No.

15
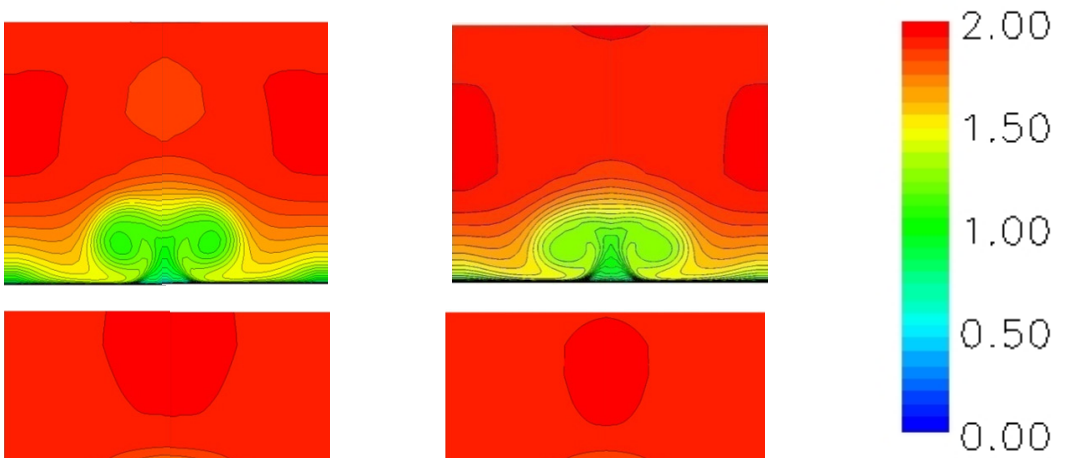

25
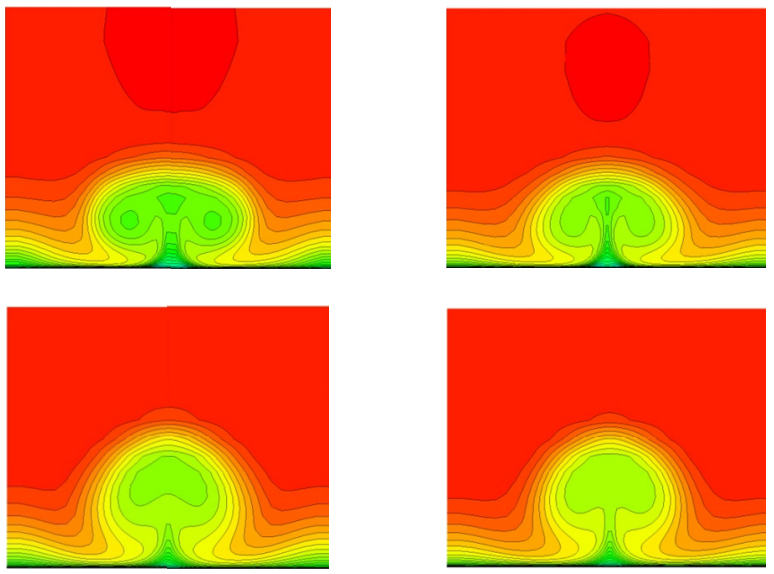

50

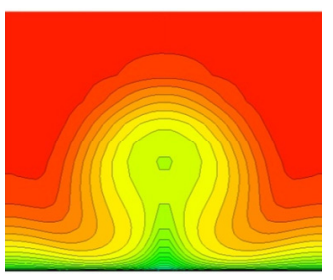

Gridded Vane

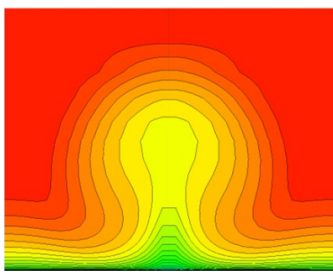

BAY Model

Figure 9.-Mach contours for a pair of counter-rotating vortex generators in Mach 2.0 flow for solutions computed with the gridded vane and using the BAY model. 


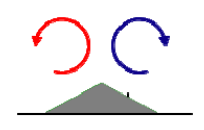

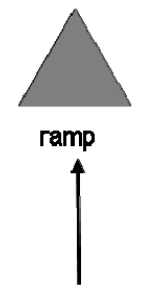

$\vec{u}$

(a)

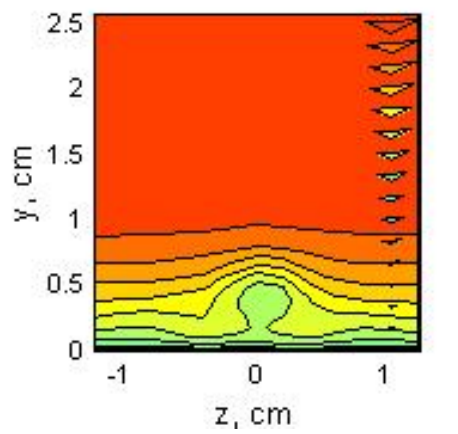

Mach No.

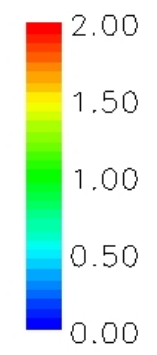

(b)

Figure 10.-Mach 2 flow over a microramp vortex generator $\Delta x / h=15$.

(a) Schematic. (b) Experimental data of Hirt et al. (Ref. 11).

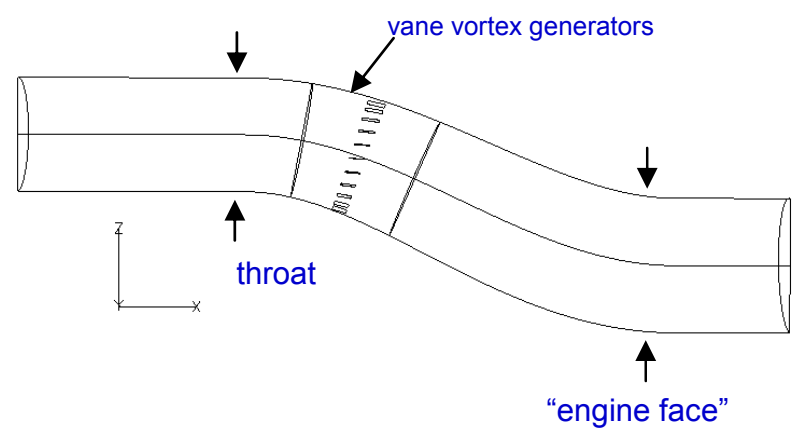

Figure 11.-Schematic of M2129 S-duct (Ref. 13).

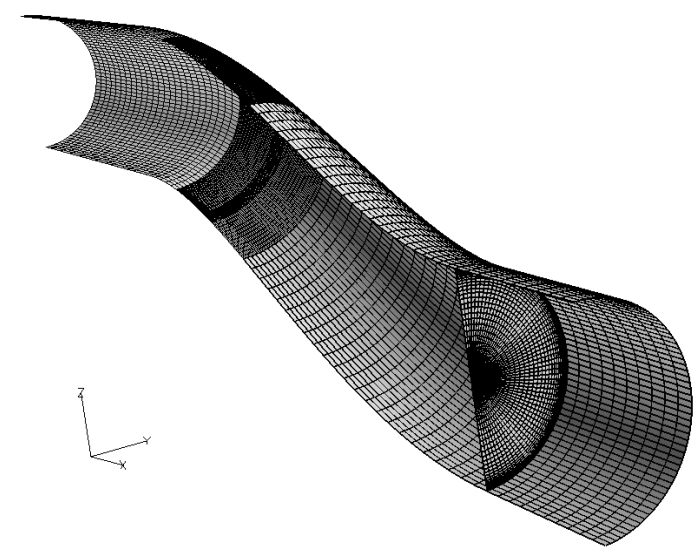

Figure 12.-Computational mesh. 


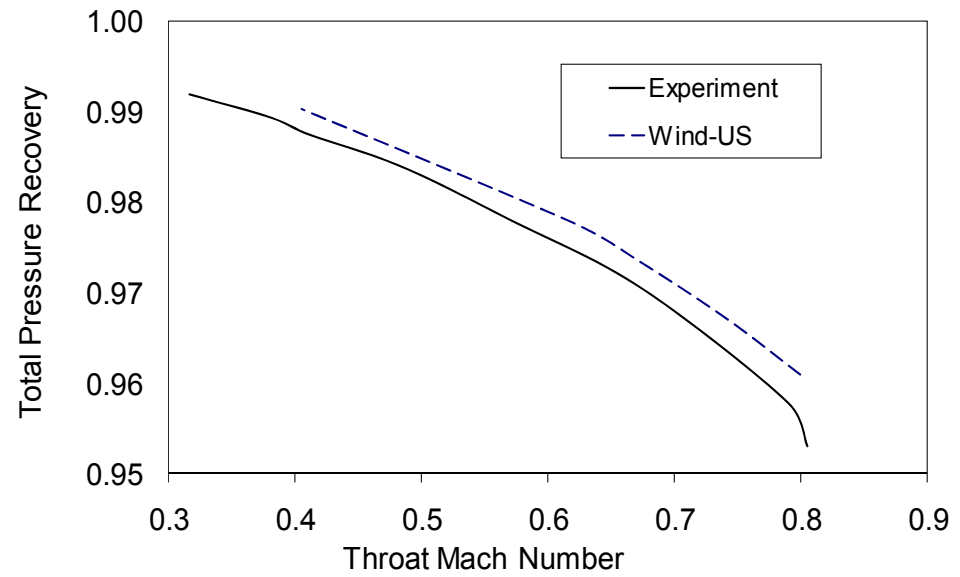

(a) Baseline Duct

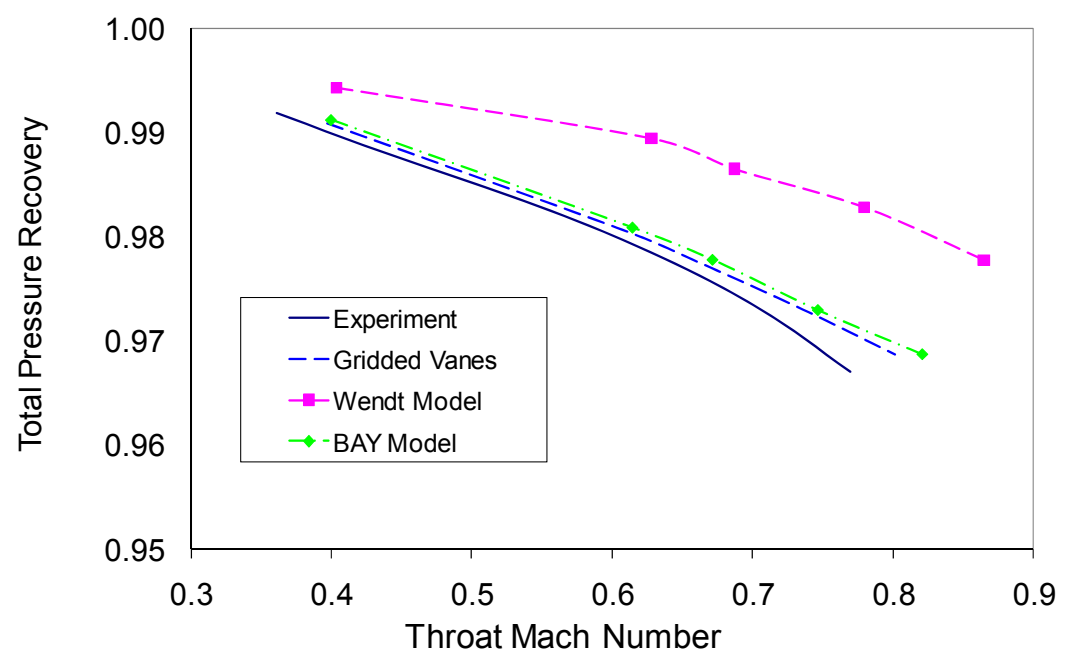

(b) Duct with VGs

Figure 13.-Total pressure recovery in the M2129 S-duct. 

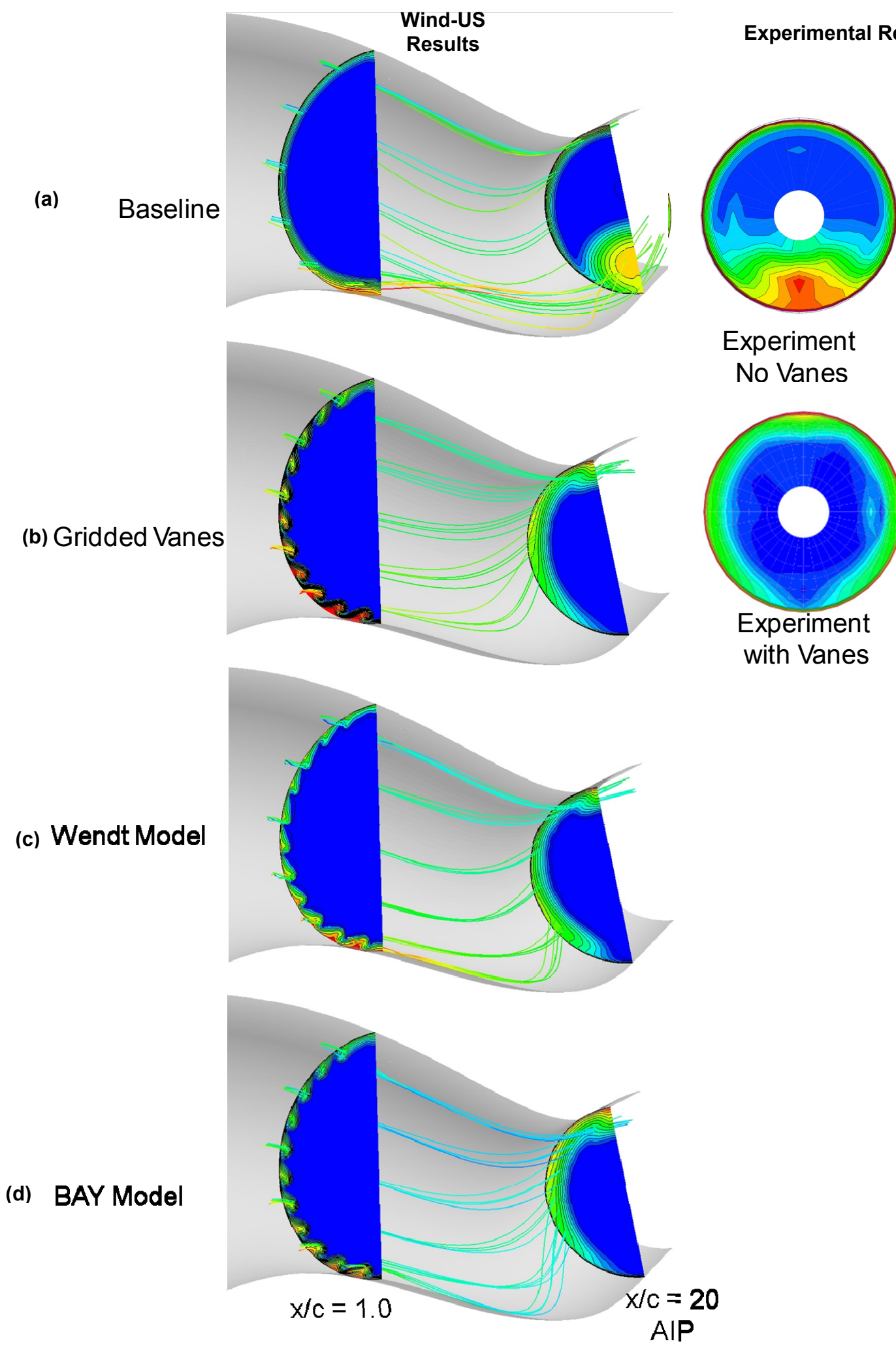

Experiment

No Vanes

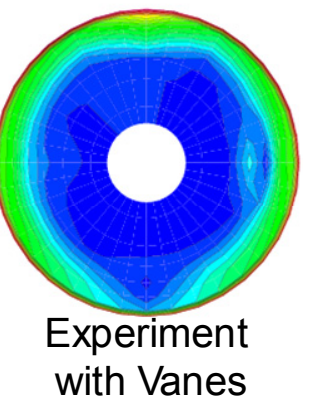

\section{with Vanes}

Figure 14.-Total pressure contours for flow through an S-duct with throat Mach number of 0.82 for: (a) the baseline case (no VGs), (b) solution with gridded vanes, (c) solution computed using the Wendt VG model and (d) solution computed using the BAY model. 


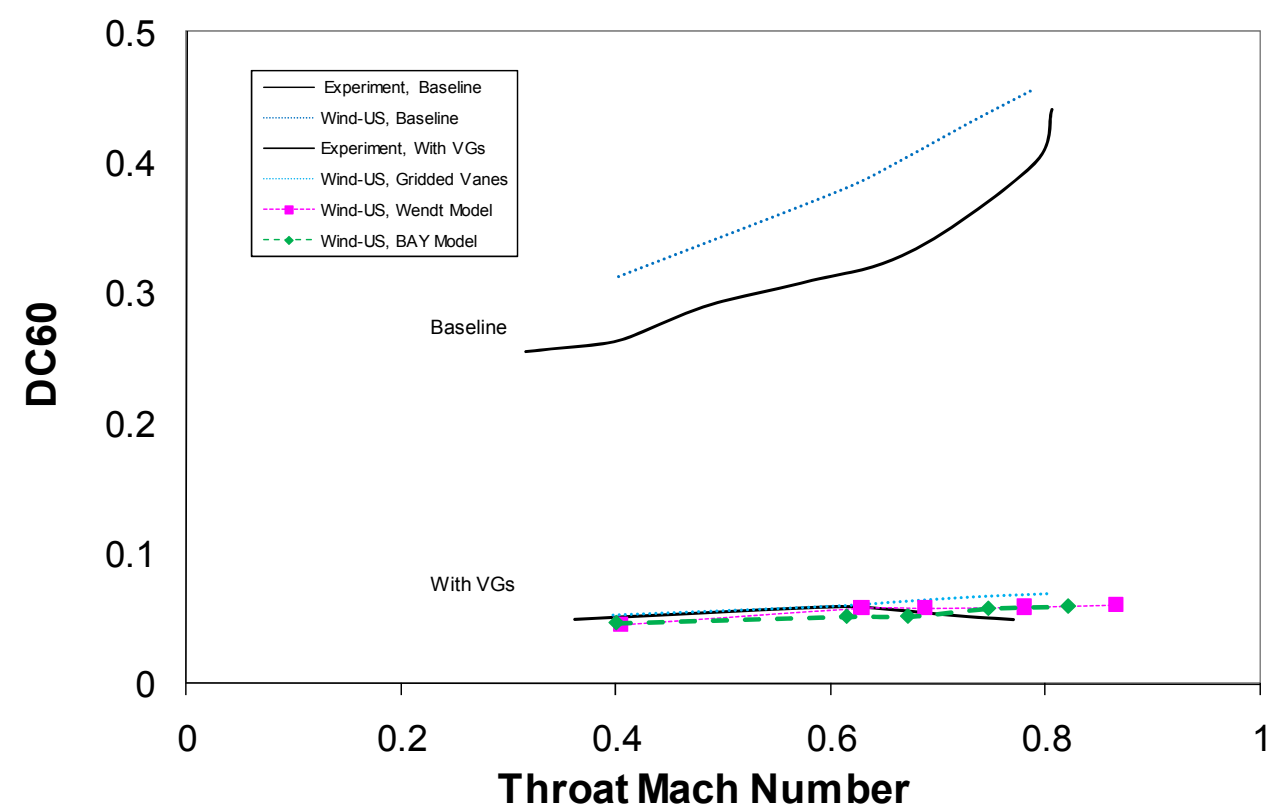

Figure 15.-DC60 distortion at the AIP for the M2129 S-duct, shown with and without vortex generators. 


\begin{tabular}{|c|c|c|c|c|c|}
\hline \multicolumn{5}{|c|}{ REPORT DOCUMENTATION PAGE } & $\begin{array}{c}\text { Form Approved } \\
\text { OMB No. 0704-0188 }\end{array}$ \\
\hline \multicolumn{6}{|c|}{ 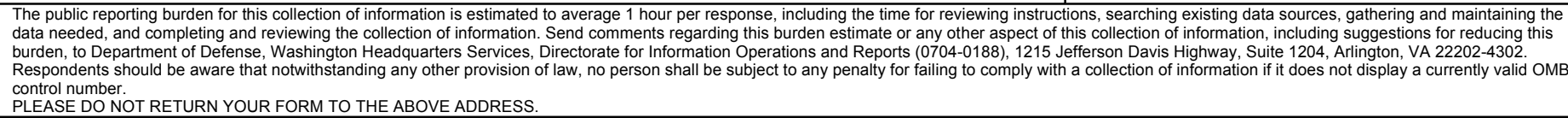 } \\
\hline \multicolumn{2}{|c|}{$\begin{array}{l}\text { 1. REPORT DATE }(D D-M M-Y Y Y Y) \\
01-07-2010\end{array}$} & \multicolumn{3}{|c|}{$\begin{array}{l}\text { 2. REPORT TYPE } \\
\text { Technical Memorandum }\end{array}$} & 3. DATES COVERED (From - To) \\
\hline \multirow{3}{*}{\multicolumn{5}{|c|}{$\begin{array}{l}\text { 4. TITLE AND SUBTITLE } \\
\text { Modeling Vortex Generators in the Wind-US Code }\end{array}$}} & 5a. CONTRACT NUMBER \\
\hline & & & & & 5b. GRANT NUMBER \\
\hline & & & & & 5c. PROGRAM ELEMENT NUMBER \\
\hline \multirow{3}{*}{\multicolumn{5}{|c|}{$\begin{array}{l}\text { 6. AUTHOR(S) } \\
\text { Dudek, Julianne, C. }\end{array}$}} & 5d. PROJECT NUMBER \\
\hline & & & & & 5e. TASK NUMBER \\
\hline & & & & & $\begin{array}{l}\text { 5f. WORK UNIT NUMBER } \\
\text { WBS 984754.02.07.03.13.02 }\end{array}$ \\
\hline \multicolumn{5}{|c|}{$\begin{array}{l}\text { 7. PERFORMING ORGANIZATION NAME(S) AND ADDRESS(ES) } \\
\text { National Aeronautics and Space Administration } \\
\text { John H. Glenn Research Center at Lewis Field } \\
\text { Cleveland, Ohio 44135-3191 }\end{array}$} & $\begin{array}{l}\text { 8. PERFORMING ORGANIZATION } \\
\text { REPORT NUMBER } \\
\text { E-17321 }\end{array}$ \\
\hline \multirow{2}{*}{\multicolumn{5}{|c|}{$\begin{array}{l}\text { 9. SPONSORING/MONITORING AGENCY NAME(S) AND ADDRESS(ES) } \\
\text { National Aeronautics and Space Administration } \\
\text { Washington, DC 20546-0001 }\end{array}$}} & $\begin{array}{l}\text { 10. SPONSORING/MONITOR'S } \\
\text { ACRONYM(S) } \\
\text { NASA }\end{array}$ \\
\hline & & & & & $\begin{array}{l}\text { 11. SPONSORING/MONITORING } \\
\text { REPORT NUMBER } \\
\text { NASA/TM-2010-216744 }\end{array}$ \\
\hline \multicolumn{6}{|c|}{$\begin{array}{l}\text { 12. DISTRIBUTION/AVAILABILITY STATEMENT } \\
\text { Unclassified-Unlimited } \\
\text { Subject Categories: } 01,05,07 \text {, and } 34 \\
\text { Available electronically at http://gltrs.grc.nasa.gov } \\
\text { This publication is available from the NASA Center for AeroSpace Information, 443-757-5802 }\end{array}$} \\
\hline \multicolumn{6}{|c|}{ 13. SUPPLEMENTARY NOTES } \\
\hline \multicolumn{6}{|c|}{$\begin{array}{l}\text { 14. ABSTRACT } \\
\text { A source term model which simulates the effects of vortex generators was implemented into the Wind-US Navier Stokes code. The source } \\
\text { term added to the Navier-Stokes equations simulates the lift force which would result from a vane-type vortex generator in the flowfield. } \\
\text { The implementation is user-friendly, requiring the user to specify only three quantities for each desired vortex generator: the range of grid } \\
\text { points over which the force is to be applied and the planform area and angle of incidence of the physical vane. The model behavior was } \\
\text { evaluated for subsonic flow in a rectangular duct with a single vane vortex generator, supersonic flow in a rectangular duct with a counter- } \\
\text { rotating vortex generator pair, and subsonic flow in an S-duct with } 22 \text { co-rotating vortex generators. The validation results indicate that the } \\
\text { source term vortex generator model provides a useful tool for screening vortex generator configurations and gives comparable results to } \\
\text { solutions computed using a gridded vane. }\end{array}$} \\
\hline \multicolumn{6}{|c|}{$\begin{array}{l}\text { 15. SUBJECT TERMS } \\
\text { Vortex generators; Computational fluid dynamics; Inlet flow; Subsonic flow; Aerodynamics; Supersonic inlets }\end{array}$} \\
\hline \multicolumn{3}{|c|}{ 16. SECURITY CLASSIFICATION OF: } & $\begin{array}{l}\text { 17. LIMITATION OF } \\
\text { ABSTRACT }\end{array}$ & $\begin{array}{l}\text { 18. NUMBER } \\
\text { OF }\end{array}$ & $\begin{array}{l}\text { 19a. NAME OF RESPONSIBLE PERSON } \\
\text { STI Help Desk (email:help } @ \text { sti.nasa.gov) }\end{array}$ \\
\hline $\begin{array}{l}\text { a. REPORT } \\
\text { U }\end{array}$ & $\begin{array}{l}\text { b. ABSTRACT } \\
\text { U }\end{array}$ & $\begin{array}{l}\text { C. THIS } \\
\text { PAGE } \\
\text { U }\end{array}$ & UU & $\begin{array}{l}\text { PAGES } \\
27\end{array}$ & $\begin{array}{l}\text { 19b. TELEPHONE NUMBER (include area code) } \\
443-757-5802\end{array}$ \\
\hline
\end{tabular}



